\title{
The study of aquatic ecosystems as a challenge to modern realities
}

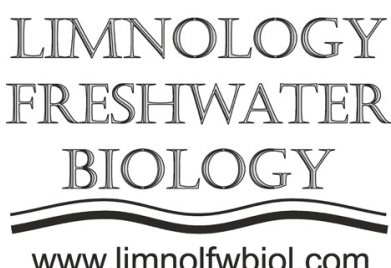

\author{
Sapozhnikova Yu.P., Galachyants A.D., Fedotov A.P. \\ Limnological Institute Siberian Branch of the Russian Academy of Sciences, Ulan-Batorskaya Str., 3, Irkutsk 664033, Russia
}

Modern realities, scientific and technological progress have posed many new, very complex global problems to humanity. Among them, of particular importance are the problems of the relationship between people and the environment. In these conditions, the only alternative to the rapid development of human civilization is sustainable development, which is impossible without a comprehensive and interdisciplinary approach to the study of ecosystems as a whole, logical combination of fundamental and applied science, studying the processes and phenomena in relation to the environment, and predicting possible changes under the influence of natural processes and anthropogenic impacts.

To assess the impact of economic activity on environmental objects and scientifically substantiate measures for the protection and rational use of the resources provided by lakes and other water bodies, it is necessary to develop new and existing directions and methods of physical, chemical and biological monitoring as well as to combine the efforts of leading experts in various fields from different cities and countries, who can share their experience.

The International Vereshchagin Baikal Conferences traditionally held every five years exactly assume a wide interdisciplinary approach and propose the involvement of specialists in various fields (including hydrobiology, hydrology, water chemistry, physics, geology, climatology, biology, etc.). The Conference has a rich history, being held every five years since 1989 at Limnological Institute SB RAS. The Vereshchagin Conferences in the memory of the outstanding Russian scientist Gleb Yu. Vereshchagin, who headed the comprehensive large-scale studies at Lake Baikal, are the largest events that represent the studies of the formation mechanisms, biodiversity, evolution of Lake Baikal, world's lakes, other water bodies and watercourses of land by methods of related sciences.

In September 2020, Limnological Institute Siberian Branch of the Russian Academy of Sciences hosts the Seventh International Vereshchagin Baikal
Conference. More than 200 scientists from Russia, Mongolia, the United Kingdom, Germany, Moldova, Armenia, France, Uzbekistan, Poland, and Japan participate in the Conference with 24 plenary, 87 oral, and 68 poster presentations. Along with the relevance of the issues addressed at the Conference, the editors of the Journal of Limnology and Freshwater Biology offer a special issue about current developments of freshwater and marine ecosystems that experience the landscape and climatic changes as well as increasing anthropogenic impact. Owing to the multidisciplinary scope of the Journal, this special issue includes 161 articles that highlight the most pressing problems of various lakes and other water bodies of the world at the moment.

The geography of the studies includes salt Lake Donuzlav (Crimea), Lake Sevan (Armenia), Japanese lakes, thermokarst lakes of a permafrost peatland, lakes of Siberia (Baikal, Teletskoye, lakes of the EravnoKhorginsky system, high-mountain lakes of Altai, and Torey lakes), Karelia (Ladoga, Onego, Krasilovskoye, Glubokoe, and Svyatozero), and lakes of the Murmansk Region. Moreover, the articles present other water bodies, such as rivers (the Volga, the Moskva, the Ob, and the Argun), reservoirs (the Moskva River reservoirs, the Karelia and East Siberia reservoirs), and seas (the Caspian Sea, the Azov Sea and the Baltic Sea).

Most articles discuss biodiversity and the sustainability mechanisms of large freshwater and marine bodies, molecular and conventional approaches for studying aquatic organisms, aspects of their genomics, physiology and biochemistry. The articles present studies of various communities of aquatic organisms, from viruses to higher plants and animals, and the influence of abiotic factors on them. The problems of fish resources in Lake Baikal and other large lakes, their formation and rational use are relevant in the articles. Particular attention is paid to current global changes in aquatic ecosystems, methods for monitoring of the aquatic environment, in particular the use of planktonic and benthic organisms as bioindicators of the state of the environment. 
Of great importance are also studies of the chemical composition of water, water exchange inside lakes, and other physical phenomena occurring both in the water column and at the water-air interface. This section discusses the causes and consequences of global changes in freshwater and marine ecosystems as well as approaches and methods for direct and remote control and monitoring of the state of the aquatic environment and measures necessary for the protection of Lake Baikal and other lakes in the world.

Finally, a large section is devoted to hydrological and hydrophysical processes and their effect on the state of aquatic environments. The articles describe processes of water balance and runoff formation, provide forecasts of the hydrological regime as well as give information about the structure of river flows, water exchange within lakes, methane in aquatic and terrestrial ecosystems, channel and coastal processes, thermal, ice and other physical phenomena.

In summary, the articles in this special issue cover a very wide range of limnological problems. We believe that this issue will enable the continued distribution of knowledge to various lakes and other water bodies of the world and suggest the recommendations for the rational use of their resources.

The Conference is funded by the Russian Foundation for Basic Research, project No. 20-0422005 (Online conferences), Helicon and SibLabService Companies. Many thanks go to those who provided manuscripts to this special issue. 